\title{
Setting up and evaluating a cognitive-behavioural therapy training programme for psychiatric trainees
}

education \& training
Psychotherapy training provision within psychiatry training schemes differs across the UK. In the light of the current changes in training structures, adjustments may be required in the way that psychotherapy training is delivered and assessed. This paper reports on the development, delivery and evaluation of a cognitivebehavioural therapy (CBT) training programme for psychiatric trainees within a training scheme with limited psychotherapy resources.

The Royal College of Psychiatrists has recognised the importance of psychotherapy training and expects all trainees in psychiatry to have an understanding of psychotherapy (Royal College Psychiatrists, 2001). Psychiatric training underwent considerable changes through the introduction of Modernising Medical Careers (Department of Health, 2004). However the new competency-based curriculum continues to highlight the expectation that by completion of training doctors will have an understanding of psychosocial therapies sufficient to treat patients using brief and supportive therapies and to know when and how to make a referral that is indicated (Royal College of Psychiatrists, 2007).

Previous studies have compared the recommendations from 1993 (Grant et al, 1993) with practice (Hamilton \& Tracy, 1996; Hwang \& Drummond, 1996; Byrne \& Meagher, 1997; Rooney \& Kelly, 1999; McCrindle et al, 2001; Podlejska-Eyres \& Stern, 2003; Carley \& Mitchinson, 2006). These studies have recommended improvements in the availability and quality of psychotherapy supervision. Research in this field has shown that in practice psychiatric training schemes often find it difficult to provide trainees with the opportunities of training to achieve the recommendations set out by the College, despite the requirement to do so to sit the MRCPsych II examination (Grant et al, 1993; Janmohamed et al, 2004). This is particularly so in settings where there is no dedicated psychotherapy post. However, bar a few exceptions (Davies, 1998; Wildgoose et al, 2002), there is a dearth of studies proposing models for improving the delivery of psychotherapy training within psychiatric training schemes.

\section{Method}

A training model was set up to deliver $\mathrm{CBT}$ training consisting of six 90-min teaching workshops after which participants took on a CBT case with supervision. Course teaching and supervision of trainees was by the authors (both hold a Diploma in CBT and have been accredited as practitioners by the British Association of Behavioural and Cognitive Psychotherapies (BABCP). Overall external supervision of the programme was by a consultant clinical psychologist with extensive experience in teaching and supervision of CBT trainees. Patients for this course were taken from a treatment waiting list for CBT and had been screened and deemed to be suitable training cases.

The teaching workshops included: (a) introduction to $C B T$, principles and the cognitive model; (b) formulation in $\mathrm{CBT}$; (c) role of thoughts in CBT, thinking errors and thought records; (d) role of behavioural techniques in CBT; (e) structuring a course of therapy; ( $f$ ) role of supervision. Following the first cohort and in response to feedback the teaching workshops were revised to include in the first session a general introduction to psychotherapy.

Trainees were then each allocated a case and expected to see their patient for up to 12 sessions of CBT, with weekly small-group supervision throughout the course. It was stipulated that trainees were required to attend at least five of the six teaching sessions prior to taking on patients and $80 \%$ of supervision sessions.

Trainee feedback and evaluation of the teaching was completed at the end of the six teaching sessions, and for clinical case supervision at the completion of the programme. A specific questionnaire was developed to evaluate the standard of teaching and case supervision, the trainee's ability to attend sessions and self-assessment of their ability to formulate a CBT case (Box 1).

The therapy tapes were used as a formative tool; trainees were encouraged to listen to their therapy tapes, and to use the Cognitive Therapy Scale (Young \& Beck, 1980) for their own self-reflection. Extracts of the sessions were listened to and used as a tool during supervision.

A joint meeting with the supervision groups took place midway through and then at the end of the 6 months to share learning experiences and receive verbal feedback about their cases and experiences of supervision.

For the completion of the training programme it was stipulated that trainees would submit a case report, there would be a final structured supervisor's report based on the key competency areas to be achieved and ongoing supervision assessments supported with the use of audiotaped therapy sessions (Box 1).

\section{Results}

\section{Case completion}

The training programme is now on its third cohort. In the first two cohorts 15 trainees in total started the teaching programme; out of these, 13 completed at least five out 
网

education \& training

\section{Box 1. Evaluation tools}

\section{Subjective evaluation tools}

Evaluation of CBT introductory sessions ${ }^{1}$

- Ability to attend sessions

- Teaching format

- Ability to participate

- Topics covered

- Standard of handouts and suggested further reading

- Ability to complete suggested homework tasks

- Understanding of CBT principles

- Ability to formulate a case in CBT terms

- Confidence in taking on a case

Evaluation of CBT supervision sessions ${ }^{1}$

- Ability to attend sessions

- Supervision format

- Ability to participate in the sessions

- Ability to understand the role of supervision in CBT

- Ability to use supervision to progress with cases

- Standard of supervision

- Understanding of the principles of CBT

- Ability to formulate a case in CBT terms

- Ability to use the formulation to guide treatment

- Confidence in taking on a case for CBT

CBT, cognitive-behavioural therapy.

1. Items on 5-point Likert scales from very poor (1) to very good (5)

\section{Objective evaluation tools}

Case report feedback form

- Structure and presentation

- Assessment procedures

- Formulation

- Intervention

- Clinical outcome

- Summary/appraisal

Structured supervisor's report

- Interpersonal skills

- Agenda setting

- Use of the formulation

- Focus on key cognitions

- Use of cognitive and behavioural interventions

- Response to supervision of six of the teaching sessions and went on to the supervision groups; 10 trainees completed seeing patients and 9 produced a case report. One of the trainees who was unable to attend the required number of teaching sessions went on to see a supervised CBT patient outside the evaluated training programme.

\section{Trainees' evaluation of teaching sessions and supervision groups}

There was very positive feedback from trainees about the ability to participate in sessions. Teaching and supervision were rated highly in terms of format, topics covered and the standard of handouts and suggested further reading lists. Following the workshop sessions trainees felt able to understand the principles of CBT and formulate a case in $\mathrm{CBT}$ terms to an adequate level. As the supervision progressed, trainees' understanding of the role of supervision in CBT and the use of supervision to progress with their patients increased. Trainees also described an increase in confidence in their ability to formulate cases in CBT terms and in taking on a CBT patient.

\section{Trainees' reflection on learning experience}

Participating in the CBT training programme had an impact on the trainees in a number of areas. Trainees reflected on their increased understanding of the CBT model, and the indications for referral to this form of treatment. They found it useful to apply 'on the spot' formulations to understand difficulties arising in the therapeutic relationship and putting into practice tools of which they only had theoretical knowledge. It was also apparent that the trainees valued the nature of the supervision they received for their cases, and because this was done in a group setting there was an opportunity also to learn from the discussions of each others' cases.

Trainees expressed an increased awareness during their regular clinical work of patients' cognitive distortions. They reported a subjective improvement in their listening skills both for content and process. As the course progressed they also felt better able to make use of supervision through self-reflection and a case-based learning approach.

Those who completed their case felt that it was a great achievement because this was the first experience with psychotherapy for all but one of the trainees in the programme. It gave trainees confidence in their ability and awakened their curiosity to explore further psychotherapy training.

\section{Supervisors' perspective}

Tapping into individual learning styles was an initial challenge, but as the groups gelled, activities such as role-playing were used and accepted much more readily. As the confidence levels increased through strengthening the theoretical underpinnings via case-based reading and practical clinical skills, more ideas were generated by group members, which enabled a much more positive learning experience. During supervision, despite some initial resistance, the use of audiotapes was valued highly and this enabled further self-reflection for the trainees. 
The structured supervisors report was helpful in evaluating the trainees level of competence and a useful tool for giving feedback to trainees.

\section{External supervisor's perspective}

The external supervisor assessed the case reports submitted by trainees, as a form of external assessment. The reports showed that overall trainees were able to use formulations to guide practice, that there was evidence of an appropriate range of CBT tools used, and of adequate use of supervision sessions. The use of case reports was seen to be an important tool to consolidate the reflective learning experience, and it was also a way to assess the level of understanding of CBT theory and practice. These reports can be kept in the trainee's portfolio.

\section{Discussion}

The programme has been evaluated positively and there continues to be a strong interest. We have been able to ensure continuity of the programme and have recruited an additional supervisor for the training. The CBT programme described was delivered in the context of a trust with limited psychotherapy resources, and the setting up and running of the programme has not been without its challenges. For trainees these challenges were attendance at the required sessions, clinical commitments, competing interests (e.g. examinations), partial shift system rotas and allocating the required $4.5 \mathrm{~h}$ per week to include therapy, case-based reading, writing up and supervision. Challenges for the supervisors included allocation of time for delivering the training and preparation of the sessions, time managing the training to tie in with the trainee's other commitments and managing the waiting list to avoid gaps between workshops and allocation of cases.

In each cohort, one of the problems has been dropout due to inability to attend sessions. It was found to be crucially important that this training activity was part of the learning contract of the trainee with their clinical supervisor and that the time was protected for this activity. Ensuring that this discussion takes place prior to joining the training has reduced further the initial attrition rate.

Management of the waiting list and advance planning with the appropriate coordinator would ensure that adequate cases are identified to avoid long gaps between the workshops and the taking up of a clinical case.

The training aims to continue to run on a 6 monthly rolling programme to coincide with change in placements of trainees - in terms of consultant support, this is the most convenient arrangement. We have explored the possibility of running the theory workshops as a standalone programme and for the trainees to be provided with case supervision from their own locality, but at present this is not a feasible option because of limited availability of CBT supervisors. This model has also been tried in the past and relies on trainees' own motivation and assertiveness to find both a case and a supervisor (Davies, 1998).

The strength of the programme outlined in this paper is in providing a clear framework of learning objectives and a continuity between the theoretical training and the case completion. The learning environment created through self-reflective practice, sharing of experiences in a group and case-based learning have all helped towards the positive outcomes of this programme. Adding assessment tools such as the case report and the supervisors' evaluation at the end of the course, which was fed back to the clinical tutor, increased the commitment to the training and its completion. The assessment tools are helpful for trainees to track their own progress, and to keep in their portfolios. They can also help to demonstrate the attainment of certain competencies.

\section{Implications for practice}

Many organisations have limited psychotherapy resources, and this can affect the extent and opportunities of psychotherapy training that are offered. The absence of a dedicated psychotherapy post or a consultant psychotherapist within a training scheme further reduces the opportunities for training. Good communication and coordination with the appropriate departments or teams is required when designing training

Box 2. Replication of the CBT training programme

\section{What is required?}

- At least a pair of enthusiastic CBT therapists with an interest in training

- 90 min per week over a 20-week period

- A further hour per week for preparation during the initial 6-week period

- Trainees who would like the opportunity to gain experience in a CBT case

- Agreement from the clinical tutor and the trainee's consultant for protected CBT time

- Commitment on the part of the trainee of about $4.5 \mathrm{~h}$ per week (including therapy supervision and private reading time)

- Liaising with the manager of the waiting list from which cases will be taken

- Supervision by an external CBT therapist once per month for the supervisors of the trainees

\section{What do you and the trust get out of it?}

- Rewarding training experience

- Reduction in waiting-list times

- Development of a special interest

- Use of creativity to transmit your skills

CBT, cognitive-behavioural therapy.

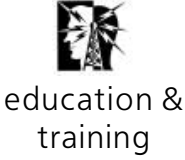

training 
F

education \& training interventions, so that they will be a benefit rather than a burden on existing services. Our experience in running this $\mathrm{CBT}$ training programme for trainees suggests that with commitment from both the trainees and supervisors it is possible to deliver a CBT training programme within a trust with low resources for psychotherapy.

Trainees responded positively to a structured CBT teaching programme and assessment of their performance. However, for trainees to fulfil the expected training requirements and achieve the agreed competencies, apart from accessibility to adequate training and supervision, there still needs to be a firm commitment for protected time and agreement within their own clinical placements and supervisors to include psychotherapy training into their learning contracts. The inclusion of clear assessment tools helped trainees to focus their learning, and their inclusion may be necessary in future psychotherapy training programmes within psychiatric training schemes in the light of the new competencybased curriculum. This model of delivery has been shown to be sustainable and effective within our trust and has a good potential for replicability in other training schemes (Box 2).

\section{Declaration of interest}

None.

\section{Acknowledgements}

The authors thank Gillian Oaker for her expertise, the clinical supervision and assessment of the case reports, and Lucy Matthews, who has been co-supervising in the programme since the second cohort.

\section{References}

BYRNE, P. \& MEAGHER, D. (1997) Psychotherapy and trainees. Psychiatric Bulletin, 21, 707-710.

CARLEY, N. \& MITCHINSON, S. (2006)

Psychotherapy training experience in the Northern Region Senior Unified SHO Scheme: present and future. Psychiatric Bulletin, 30, 390-393.

DAVIES, S. P. (1998) Psychotherapy on a shoestring: improving training using existing resources. Psychiatric Bulletin 22, 702-705.

DEPARTMENT OF HEALTH (2004) Modernising Medical Careers. The Next Steps: The Future Shape of Foundation, Specialist and General PracticeTraining Programmes. Department of Health.

GRANT, S., HOLMES, J. \& WATSON, J. (1993) Guidelines for psychotherapy training as part of general psychiatric training. Psychiatric Bulletin, 17,695698

HAMILTON, R. J. \& TRACY, D. (1996) A survey of psychotherapy training among psychiatric trainees. Psychiatric Bulletin, 20, 536-537.

HWANG, K. \& DRUMMOND, L. M. (1996) Psychotherapy training and experience of successful candidates in MRCPsych examinations. Psychiatric Bulletin, 20,604-606.

JANMOHAMED, A., WARD, A., SMITH C., et al (2004) Does protected time improve psychotherapy training in psychiatry? A response to College guidelines. Psychiatric Bulletin, 28 100-103.

MCCRINDLE, D. WILDGOOSE, J. \&

TILLETT, R. (2001) Survey of psychotherapy training for psychiatric trainees in South-West England. Psychiatric Bulletin, 25, 140-143.

PODLEJSKA-EYRES, M. \& STERN, J. (2003) Psychotherapy training experience in an inner-city psychiatry rotation. Psychiatric Bulletin, 27, 179-182.

ROONEY, S. \& KELLY, G. (1999) Psychotherapy experience in Ireland. Psychiatric Bulletin, 23, 89-94.

ROYAL COLLEGE OF PSYCHIATRISTS (2001) Requirements for Psychotherapy Training as Part of the Basic Specialist Psychiatric Training. Royal College of Psychiatrists. http://www.rcpsych.ac.uk/ PDF/ptBasic.pd

ROYAL COLLEGE OF PSYCHIATRISTS (2007) A Competency Based Curriculum for Specialist Training in Psychiatry: Curriculum Core and General Module. Royal College of Psychiatrists. http://www. rcpsych.ac.uk/training/ specialtytrainingassess.aspx/ WILDGOOSE, J., MCCRINDLE, D. \& TILLETT, R. (2002) The Exeter half-day release psychotherapy training scheme - a model for others? Psychiatric Bulletin, 26, 31-33.

YOUNG, J. E. \& BECK, A.T. (1980) The CognitiveTherapy Scale Rating Manual. University of Philadelphia. http:// www.academyofct.org/upload/ documents/CTRS_Manual.pdf

*Rebeca Martinez Section of Psychological Medicine, University of Glasgow Academic Centre, Gartnavel Royal Hospital, 1055 GreatWestern Road, Glasgow G12 0XH, email: r.martinez@clinmed.gla.ac.uk, Rebecca Horne Hellesdon Hospital, Norfolk and Waveney Mental Health Partnership 